\title{
The mitochondrial complex II and ATP-sensitive potassium channel interaction: quantitation of the channel in heart mitochondria*
}

\author{
Andrew P. Wojtovich1, Keith W. Nehrke² and Paul S. Brookes ${ }^{1 凶}$ \\ 1Department of Anesthesiology and 2Medicine, University of Rochester Medical Center, Rochester, NY, USA
}

The mitochondrial ATP-sensitive potassium channel $\left(\mathrm{mK}_{\mathrm{ATP}}\right)$ is important in cardioprotection, although the channel remains molecularly undefined. Several studies have demonstrated that mitochondrial complex II inhibitors activate the $\mathrm{mK}_{\mathrm{ATP}}$, suggesting a potential role for complex II in channel composition or regulation. However, these inhibitors activate $\mathrm{mK}_{\mathrm{ATP}}$ at concentrations which do not affect bulk complex II activity. Using the potent complex II inhibitor Atpenin A5, this relationship was investigated using tight-binding inhibitor theory, to demonstrate that only $0.4 \%$ of total complex II molecules are necessary to activate the $\mathrm{mK}_{\mathrm{ATP}}$. These results estimate the $\mathrm{mK}_{\mathrm{ATP}}$ content at 15 channels per mitochondrion.

Keywords: complex II, $\mathrm{mK}_{\text {ATP, }}$ Atpenin A5, ischemic preconditioning

Received: 31 August, 2010; revised: 31 October, 2010; accepted: 15 November, 2010; available on-line: 19 November, 2010

\section{INTRODUCTION}

The mitochondrial ATP-sensitive potassium channel $\left(\mathrm{mK}_{\text {АтP }}\right)$ is a critical component of the endogenous cardioprotective machinery of ischemic preconditioning (IPC). The activation of this channel protects against ischemia reperfusion injury via an unclear mechanism involving the prevention of mitochondrial calcium overload and reactive oxygen species overproduction, as well as mild swelling and uncoupling (reviewed in: Facundo et al., 2006). Despite intense investigation, the identity of the $\mathrm{mK}_{\text {AтP }}$ remains elusive. Pharmacological overlap between the channel and mitochondrial complex II (succinate dehydrogenase) led to the hypothesis that complex II may be a component of the $\mathrm{mK}_{\text {ATP }}$ (Ardehali et al., 2004). In this regard, pharmacological activators of the $\mathrm{mK}_{\mathrm{ATP}}$ were found to inhibit complex II (Ockaili et al., 2001; Ardehali et al., 2004; Wojtovich \& Brookes, 2009; Wojtovich \& Brookes, 2008). However, the effects of compounds such as diazoxide on the $\mathrm{mK}_{\text {ATP }}$ were seen at concentrations sometimes orders of magnitude below those required for complex II inhibition. Therefore, the effect on complex II activity at high concentrations was divorced from the mechanism of channel activation. The relationship between complex II and the channel was further investigated using the complex II inhibitor Atpenin A5 (AA5) (Wojtovich \& Brookes, 2009). AA5 is a potent and specific complex II inhibitor with an $\mathrm{IC}_{50}$ of $10 \mathrm{nM}$ (Miyadera et al., 2003) yet like the $\mathrm{mK}_{\text {ATP }}$ opener diazoxide, AA5 opens the channel at a concentration an order of magnitude below that (Wojtovich \& Brookes, 2009).

To provide insight to the nature of the $\mathrm{mK}_{\mathrm{ATP}}$, tightbinding inhibitor theory was applied herein. This theory defines a tight binding inhibitor as one which exerts its effect on an enzyme catalyzed reaction at a concentration comparable to that of the enzyme. The theory has been used to determine the number of adenine nucleotide translocator molecules by titrating in its selective inhibitor carboxyatractylate (Streicher-Scott et al., 1993; Brand et al., 2005). In this regard, AA5 can be considered a highly selective inhibitor of complex II since an $\mathrm{IC}_{50}$ of $10 \mathrm{nM}$ is sufficiently low relative to the amount of protein present. Thus, by titrating AA5, the total number of complex II molecules as well as the number of complex II molecules resulting in the activation of the $\mathrm{mK}_{\mathrm{ATP}}$ channel, can be determined.

\section{MATERIALS AND METHODS}

Animals. Sprague-Dawley rats, 200-225 g, were purchased from Harlan (Indianapolis, IN, USA) and housed on a $12 \mathrm{~h}$ light/dark cycle with food and water available ad libitum. All procedures were performed in accordance with the US National Institutes of Health "Guide for the care and use of laboratory animals", and were approved by the University of Rochester's Committee on Animal Resources.

Cardiac mitochondria. Mitochondria were rapidly isolated by differential centrifugation in sucrose-based buffer $(300 \mathrm{mM}$ sucrose, $20 \mathrm{mM}$ Tris, $2 \mathrm{mM}$ EGTA, $\mathrm{pH} 7.35$, at $4^{\circ} \mathrm{C}$ ) as previously described (Wojtovich \& Brookes, 2008).

Complex II enzymatic activity. Complex II activity was determined spectrophotometrically as the thenoyltrifluoroacetone sensitive rate of succinate-driven, coenzyme $\mathrm{Q}_{2}$-linked reduction of dichlorophenolindophenol (DCPIP), as previously described (Wojtovich \& Brookes, 2008). Briefly, mitochondria $(0.05 \mathrm{mg} / \mathrm{ml})$ were added to a $50 \mathrm{mM} \mathrm{K}^{+} \mathrm{PO}_{4}^{-}$buffer $\left(\mathrm{pH} 7.4\right.$, at $37^{\circ} \mathrm{C}$ ) containing $100 \mu \mathrm{M}$ EDTA, $40 \mu \mathrm{M}$ DCPIP, $1 \mathrm{mM} \mathrm{KCN}, 10 \mu \mathrm{M}$ rotenone, and $50 \mu \mathrm{M}$ coenzyme $\mathrm{Q}_{2}$. The reduction of

\footnotetext{
e-mail: paul_brookes@urmc.rochester.edu

* This work was presented in the poster form at the 16th European Bioenergetics Conference (Warsaw, 2010); abstract in Biochim Biophys Acta, 1797 (Suppl): 81 (2010).

Abbreviations: AA5, Atpenin A5; $\mathrm{mK}_{\text {}}$ mitochondrial ATP-sensitive potassium channel; SUR, sulfonylurea receptor; Kir, inwardly rectifying potassium channel
} 
DCPIP $\left(\varepsilon=21000 \mathrm{M}^{-1} \cdot \mathrm{cm}^{-1}\right)$ to $\mathrm{DCPIPH}_{2}$ was initiated by addition of $20 \mathrm{mM}$ succinate.

mK $_{\text {ATP }}$ osmotic swelling assay. Using a Beckman DU800 spectrophotometer, $\mathrm{mK}_{\mathrm{ATP}}$ activity was monitored at $520 \mathrm{~nm}$ as light scatter (optical density) change due to $\mathrm{K}^{+}$uptake and swelling, as previously described (Wojtovich \& Brookes, 2008). Briefly, mitochondria (0.25 $\mathrm{mg} / \mathrm{ml}$ ) were added rapidly to a stirring cuvette containing $\mathrm{mK}_{\mathrm{ATP}}$ swelling buffer $(100 \mathrm{mM} \mathrm{KCl}, 10 \mathrm{mM}$ Hepes, $2 \mathrm{mM} \mathrm{MgCl}_{2}, 2 \mathrm{mM} \mathrm{KH_{2 }} \mathrm{PO}_{4}, 1 \mu \mathrm{g} / \mathrm{ml}$ oligomycin, $\mathrm{pH}$ 7.2 , at $37^{\circ} \mathrm{C}$ ) and substrates/inhibitors as indicated in the figures. All measurements were taken within $1.5 \mathrm{~h}$ of mitochondrial isolation (Wojtovich \& Brookes, 2008).

\section{RESULTS}

\section{Complex II enzymatic activity and the measurement of complex II content by AA5 titer}

AA5 is a potent and specific complex II inhibitor; therefore, the minimum amount of AA5 required to inhibit complex II activity equals the amount of complex II present. Complex II activity was inhibited successively by additions of AA5 and plotted as percent inhibition (Fig. 1). The amount of AA5 added was expressed as nmol AA $5 / \mathrm{mg}$ protein. The minimum AA 5 titer was determined as the intercept between the steepest slope and the maximal complex II inhibition (100\%) (Fig. 1B). The titration of AA5 revealed a content of complex II

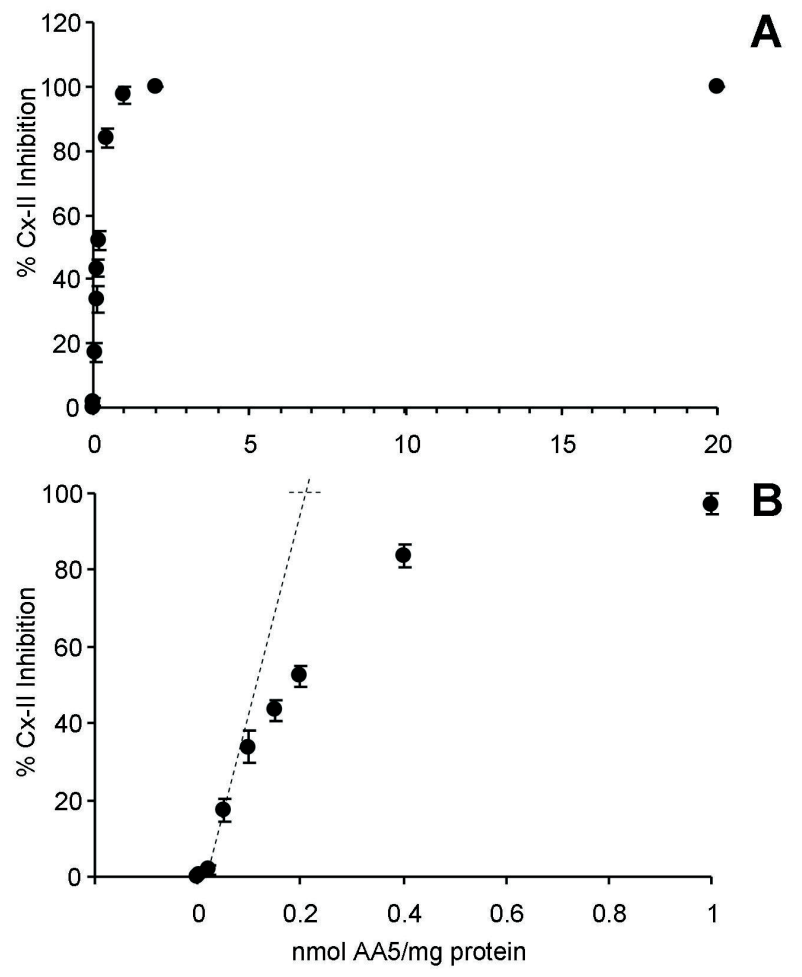

Figure 1. Complex II content of rat heart mitochondria

(A) The complex II content was determined via an AA5 titer of complex II activity. Complex II activity was measured and expressed as percent inhibition. (B) The expanded range of 0 to 1 $\mathrm{nmol} A \mathrm{~A} 5 / \mathrm{mg}$ protein illustrates the determination of the steepest slope. Complex II content was measured as the intersection where the steepest slope in the AA5 titer crosses the maximal inhibition of complex II activity (100\%) and is denoted with a dashed line. Data are mean \pm S.E.M., $n=4$. of 0.209 nmol AA5 $/ \mathrm{mg}$ mitochondrial protein. The crystallization of AA5 with complex II determined that one molecule of AA5 binds per complex II molecule (Horsefield et al., 2006) thereby yielding 0.209 nmol complex $\mathrm{II} / \mathrm{mg}$ protein, or about $3 \%$ of total mitochondrial protein (assuming a molecular mass of $140 \mathrm{kDa}$ for complex II).

\section{Measurement of complex II content required for AA5- mediated $\mathrm{mK}_{\mathrm{ATP}}$ activation}

The pharmacological overlap between complex II and the $\mathrm{mK}_{\text {ATP }}$ suggests a regulatory role for complex II in channel activity. Interestingly, the potent complex II inhibitor AA5 is also the most potent $\mathrm{mK}_{\text {ATP }}$ opener discovered to date (Wojtovich \& Brookes, 2009). AA5 was titrated and $\mathrm{mK}_{\mathrm{ATP}}$ activity was monitored via swelling. The $\mathrm{mK}_{\mathrm{ATP}}$-mediated swelling relies on membranepotential driven $\mathrm{K}^{+}$uptake and the AA5 titer was determined using different substrates. Concentrations of AA5 $>2.5 \mathrm{nM}$ inhibited $\mathrm{mK}_{\text {ATP }}$ activity when succinate was used as the substrate (Figs. 2C and D). However, this effect was not seen when glutamate/malate was used as the substrate (Figs. 2A and B) and thus we attribute the loss of $\mathrm{mK}_{\text {АTP }}$ activity seen with succinate due to the inhibition of membrane-potential driven $\mathrm{K}^{+}$uptake (Wojtovich \& Brookes, 2009). Channel activity was monitored at different concentrations of AA5 and plotted as percent of control (open channel). Again, the amount of AA5 added was expressed as nmol AA $5 / \mathrm{mg}$ protein. The minimum AA5 titer was determined as the intercept between the steepest slope and the maximal $\mathrm{mK}_{\mathrm{ATP}}$ activity (control, 100\%) (Figs. 2B and D). Using both complex I and complex II-linked substrates the complex II content required for AA5-mediated $\mathrm{mK}_{\mathrm{ATP}}$ activation was calculated to be either 0.864 or $0.816 \mathrm{pmol}$ complex $\mathrm{II} / \mathrm{mg}$ of protein, respectively. This is approx. 250-fold lower than the level of complex II enzymatic activity (vide supra).

\section{DISCUSSION}

The results from Figs. 1 and 2, demonstrate the disconnect between $\mathrm{mK}_{\text {ATP }}$ opening and complex II inhibition using an inhibitor of complex II, such that AA5 optimally opened the $\mathrm{mK}_{\mathrm{ATP}}$ channel at a concentration that had no effect on complex II activity. Furthermore, previous work has demonstrated that the opening effect of AA5 was still present under conditions that did not require complex II activity (e.g., glutamate/malate, and ascorbate/TMPD), suggesting a more direct role for complex II in the regulation of the channel and not secondary effects due to simply inhibiting complex II (e.g., changes in ROS generation by the complex) (Wojtovich $\&$ Brookes, 2009). The profile of activating the channel at concentrations which have no effect on total complex II activity is now reported for six compounds (nitro-linoleic acid, nitroxyl, malonate; 3-nitropropionate, Atpenin A5, and diazoxide) (Schafer et al., 1969; Garlid et al., 1997; Ockaili et al., 2001; Ardehali et al., 2004; Wojtovich \& Brookes, 2008; Wojtovich \& Brookes, 2009; Queliconi et al., 2010). These compounds all inhibit complex II via different mechanisms and bind to different subunits of complex II, and emphasize the critical role complex II plays in the regulation or formation of the channel.

Given that AA5 is a tight binding specific inhibitor of complex II, the minimum amount of AA5 required to inhibit complex II equals the amount of complex II 

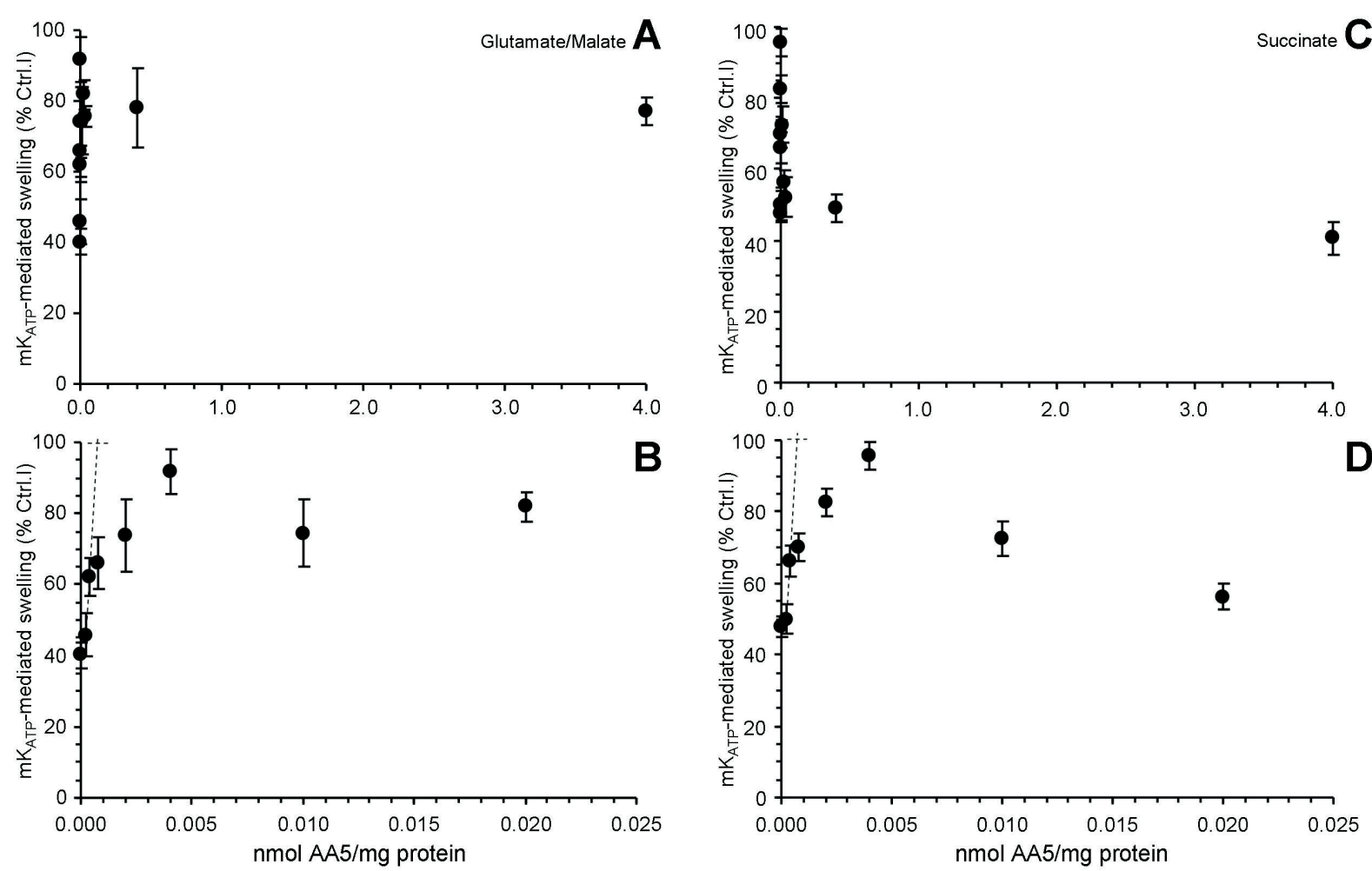

Figure 2. Complex II content required for $\mathrm{mK}_{\mathrm{ATP}}$ activity

The AA5 titer was investigated using both succinate (A) and glutamate/malate (B) to drive respiration. $\mathrm{mK}_{\text {ATP }}$ activity was determined via $\mathrm{mK}_{\text {ATP }}$-mediated swelling and expressed as a percent of maximal $\mathrm{mK}_{\text {ATP }}$ activity (e.g. control, $100 \%$ ). The range of 0 to $0.02 \mathrm{nmol}$ AA5/mg protein was expanded illustrates the determination of the steepest slope using both succinate (C) and glutamate/malate (D). Complex II content was measured as the intersection where the steepest slope in the AA5 titer crosses the maximal mK $_{\text {ATP }}$ activity $(100 \%)$ and is denoted with a dashed line. Data are mean \pm S.E.M., $N \geq 8$.

present, since there is a $1: 1$ ratio of complex II to AA5 (Horsefield et al., 2006). The total number of complex II molecules per $\mathrm{mg}$ of mitochondria was determined from Fig. 1 by titrating AA5 and monitoring complex II activity. Assuming $8.7 \times 10^{9}$ mitochondria per $\mathrm{mg}$ of protein (Schwerzmann et al., 1986), the number of complex II molecules per mitochondrion was estimated at 14,494 (0.209 nmol/mg protein). While the amount of complex II per mitochondrion is largely species and tissue specific, other reports of complex II content range $0.074 \mathrm{nmol} / \mathrm{mg}$ protein in rat liver (Schwerzmann et al., 1986 ) to $0.330 \mathrm{~mol} / \mathrm{mg}$ protein in cat skeletal muscle (Schwerzmann et al., 1989). However, when comparing the same species and accounting for the difference in surface density (520 and 2,000 $\mathrm{cm}^{2}$ of inner membrane/ mg protein in liver and heart, respectively) the amount of complex II per mitochondrion is in close agreement (Schwerzmann et al., 1986).

The number of complex II molecules necessary to activate the $\mathrm{mK}_{\text {ATP }}$ was determined from Fig. 2 using both complex II- and complex I-linked substrates. Both conditions yielded a similar result, such that 57 and 60 complex II molecules are necessary to activate the $\mathrm{mK}_{\text {ATP }}$ for succinate and glutamate/malate, respectively. Therefore, although using a complex II inhibitor, only a small pool of inhibited-complex II molecules (e.g., 0.4\%) are necessary to maximally open the channel thereby having a negligible effect on total complex II activity. The data presented herein also implies that the number of $\mathrm{mK}_{\text {ATP }}$ channels present in a mitochondrion is relatively small, which would be hypothesized based upon the bioenergetic consequence of having large scale $\mathrm{K}^{+}$influx into the mitochondrion. Assuming one complex II per functional $\mathrm{mK}_{\text {ATP }}$ channel, then the number of functional channels per mitochondrion is estimated at 60 .

The $\mathrm{mK}_{\text {ATP }}$ is hypothesized to resemble the molecularly defined surface $K_{\text {ATP }}$ (Paucek et al., 1992; Mironova et al., 2004) which is an octamer composed of four identical inwardly rectifying potassium channel (Kir) and four sulfonylurea receptor (SUR) subunits (Nichols, 2006). While recent evidence supports the existence of a bona fide $\mathrm{K}^{+}$channel, with pharmacological sensitivities resembling Kir6.2 (Wojtovich et al., 2010), the role of a SUR in $\mathrm{mK}_{\text {ATP }}$ composition remains elusive. While a short form SUR subunit was found in mitochondria, it is not a component of the $\mathrm{mK}_{\mathrm{ATP}}$ channel (Ye et al., 2009). Without the molecular identity of the channel, the nature of the complex II and $\mathrm{mK}_{\text {ATP }}$ interaction and the exact stoichemometry of complex II to $\mathrm{mK}_{\text {ATP }}$ remains unknown.

It is possible that the $\mathrm{mK}_{\mathrm{ATP}}$ lacks a SUR subunit. Indeed, using arteries from SUR2 ${ }^{-/}$mice it was demonstrated that vasodilation responses to diazoxide and AA5 are independent of SUR ablation (Adebiyi et al., 2008). Thus it can be hypothesized that complex II may replace SUR subunits, interacting with the $\mathrm{mK}_{\text {ATP }}$ in a similar manner as the channel's own subunits (i.e., Kir/ SUR). Thus, each functional $\mathrm{mK}_{\text {ATP }}$ channel would contain 4 molecules of complex II, and based on the AA5 titrations herein this would yield an estimate of about $15 \mathrm{mK}_{\text {ATP }}$ molecules per mitochondrion. This number is based upon the assumption that every inhibited complex II molecule is able interact with a channel; however, it is more often the case that the modulator is present in ex- 
cess and the exact number of channel may be even less. This low abundance could also account for the challenge of defining the $\mathrm{mK}_{\text {ATP }}$ on a molecular level.

The results herein demonstrate the relationship between complex II and the $\mathrm{mK}_{\mathrm{ATP}}$, and provide an explanation for the conundrum of using a complex II inhibitor to open the $\mathrm{mK}_{\mathrm{ATP}}$ but at a concentration which does not inhibit complex II (Wojtovich \& Brookes, 2009). Tight-binding inhibitor theory demonstrates that only a small pool of complex II molecules $(0.4 \%)$ is necessary to activate the $\mathrm{mK}_{\text {ATP }}$, thus leaving the bulk of complex II activity unaffected. This finding has implications for the specificity and mechanism of the $\mathrm{mK}_{\text {ATP }}$ activator diazoxide. Similar to AA5, diazoxide activates the $\mathrm{mK}_{\text {ATP }}$ at low concentrations $(<30 \mu \mathrm{M}$ ) (Facundo et al., 2007; Wojtovich et al., 2010), and inhibits complex II $(>100 \mu \mathrm{M})$ (Schafer et al., 1969; Dzeja et al., 2003). Originally, the "side-effect" of complex II inhibition was divorced from the mechanism of action since the concentrations of diazoxide that activated the $\mathrm{mK}_{\mathrm{ATP}}$ are 3-10 times less than those needed for complex II inhibition. This data suggests that, like AA5, diazoxide may exert its effect on the $\mathrm{mK}_{\text {ATP }}$ via complex II since only a small fraction of the complex II pool is necessary. This complex II-mechanism would also explain the specificity of diazoxide for the $\mathrm{mK}_{\text {ATP }}$ over the surface channel (Garlid et al., 1997), since complex II is not expected to be found at the cell surface.

In conclusion, complex II is an important regulator or component of the $\mathrm{mK}_{\text {ATP }}$. The interaction between complex II and the channel is brought about through the inhibition of complex II activity. The mechanism of this interaction is not yet known. However, inhibition of the total complex II pool is not necessary and maximal activation the $\mathrm{mK}_{\text {ATp }}$ via this mechanism requires $0.4 \%$ of the total complex molecules to be inhibited. At a time when the $\mathrm{mK}_{\text {ATP }}$ identity remains elusive, the exploitation of the complex II-mediated channel opening mechanism provides a unique means to design potent and specific $\mathrm{mK}_{\text {ATP }}$ activators.

\section{Acknowledgements}

We thank Emily K. Redman for technical assistance.

This work was funded by American Heart Association (Founders Affiliate) Predoctoral Fellowship 0815770D (to A.P.W.) and US National Institutes of Health grants R01-HL071158 (to P.S.B.) and R01-GM-087483 (to P.S.B. and K.W.N.).

\section{REFERENCES}

Adebiyi A, McNally EM, Jaggar JH (2008) Sulfonylurea receptor-dependent and -independent pathways mediate vasodilation induced by ATP-sensitive K+ channel openers. Mol Pharmacol 74: 736-743.

Ardehali H, Chen Z, Ko Y, Mejia-Alvarez R, Marban E (2004) Multiprotein complex containing succinate dehydrogenase confers mitochondrial ATP-sensitive K+ channel activity. Proc Natl Acad Sci USA 101: 11880-11885.

Brand MD, Pakay JL, Ocloo A, Kokoszka J, Wallace DC, Brookes PS, Cornwall EJ (2005) The basal proton conductance of mitochondria depends on adenine nucleotide translocase content. Biochem I 392: 353-362.

Dzeja PP, Bast P, Ozcan C, Valverde A, Holmuhamedov EL, Van Wylen DG, Terzic A (2003) Targeting nucleotide-requiring enzymes: implications for diazoxide-induced cardioprotection. Am J Physiol Heart Circ Physiol 284: H1048-H1056.

Facundo HT, Fornazari M, Kowaltowski AJ (2006) Tissue protection mediated by mitochondrial $\mathrm{K}+$ channels. Biochim Biophys Acta 1762: 202-212.

Facundo HT, de Paula JG, Kowaltowski AJ (2007) Mitochondrial ATP-sensitive $\mathrm{K}+$ channels are redox-sensitive pathways that control reactive oxygen species production. Free Radic Biol Med 42: 1039-1048.

Garlid KD, Paucek P, Yarov-Yarovoy V, Murray HN, Darbenzio RB, D'Alonzo AJ, Lodge NJ, Smith MA, Grover GJ (1997) Cardioprotective effect of diazoxide and its interaction with mitochondrial ATP-sensitive $\mathrm{K}+$ channels. Possible mechanism of cardioprotection. Circ Res 81: 1072-1082.

Horsefield R, Yankovskaya V, Sexton G, Whittingham W, Shiomi K, Omura S, Byrne B, Cecchini G, Iwata S (2006) Structural and computational analysis of the quinone-binding site of complex II (succinate-ubiquinone oxidoreductase): a mechanism of electron transfer and proton conduction during ubiquinone reduction. J Biol Chem 281: 7309-7316.

Mironova GD, Negoda AE, Marinov BS, Paucek P, Costa AD, Grigoriev SM, Skarga YY, Garlid KD (2004) Functional distinctions between the mitochondrial ATP-dependent $\mathrm{K}+$ channel (mitoK $\mathrm{K}_{\text {ATP }}$ ) and its inward rectifier subunit (mitoKIR). J Biol Chem 279: 3256232568.

Miyadera H, Shiomi K, Ui H, Yamaguchi Y, Masuma R, Tomoda H, Miyoshi H, Osanai A, Kita K, Omura S (2003) Atpenins, potent and specific inhibitors of mitochondrial complex II (succinate-ubiquinone oxidoreductase). Proc Natl Acad Sci USA 100: 473-477.

Nichols CG (2006) KATP channels as molecular sensors of cellular metabolism. Nature 440: 470-476.

Ockaili RA, Bhargava P, Kukreja RC (2001) Chemical preconditioning with 3-nitropropionic acid in hearts: role of mitochondrial K(ATP) channel. Am J Physiol Heart Circ Physiol 280: H2406-H2411.

Paucek P, Mironova G, Mahdi F, Beavis AD, Woldegiorgis G, Garlid KD (1992) Reconstitution and partial purification of the glibenclamide-sensitive, ATP-dependent $\mathrm{K}+$ channel from rat liver and beef heart mitochondria. J Biol Chem 267: 26062-26069.

Queliconi BB, Wojtovich AP, Nadtochiy SM, Kowaltowski AJ, Brookes PS (2010) Redox regulation of the mitochondrial $K_{\text {ATP }}$ channel in cardioprotection. Biochim Biophysa Acta - Mol Cell Res doi:10.1016/j. bbamcr.2010.11.005.

Schafer G, Wegener C, Portenhauser R, Bojanovski D (1969) Diazoxide, an inhibitor of succinate oxidation. Biochem Pharmacol 18: 26782681.

Schwerzmann K, Cruz-Orive LM, Eggman R, Sanger A, Weibel ER (1986) Molecular architecture of the inner membrane of mitochondria from rat liver: a combined biochemical and stereological study. J Cell Biol 102: 97-103.

Schwerzmann K, Hoppeler H, Kayar SR, Weibel ER (1989) Oxidative capacity of muscle and mitochondria: correlation of physiological, biochemical, and morphometric characteristics. Proc Natl Acad Sci USA 86: 1583-1587.

Streicher-Scott J, Lapidus R, Sokolove PM (1993) Use of carboxyatractylate and tight-binding inhibitor theory to determine the concentration of functional mitochondrial adenine nucleotide translocators in a reconstituted system. Anal Biochem 210: 69-76.

Wojtovich AP, Brookes PS (2008) The endogenous mitochondrial complex II inhibitor malonate regulates mitochondrial ATP-sensitive potassium channels: Implications for ischemic preconditioning. Biochim Biophys Acta 1777: 882-889.

Wojtovich AP, Brookes PS (2009) The complex II inhibitor atpenin A5 protects against cardiac ischemia-reperfusion injury via activation of mitochondrial $K_{\text {ATP }}$ channels. Basic Res Cardiol 104: 121-129.

Wojtovich AP, Williams DM, Karcz MK, Lopes CM, Gray DA, Nehrke KW, Brookes PS (2010) A novel mitochondrial $K_{\text {АтP }}$ channel assay. Circ Res 106: 1190-1196.

Ye B, Kroboth SL, Pu JL, Sims JJ, Aggarwal NT, McNally EM, Makielski JC, Shi NQ (2009) Molecular identification and functional characterization of a mitochondrial sulfonylurea receptor 2 splice variant generated by intraexonic splicing. Circ Res 105: 1083-1093. 